\title{
ADSORÇÃO DE ATRAZINA, DESETILATRAZINA E HIDROXIATRAZINA EM LATOSSOLO VERMELHO ESCURO SOB CERRADO E SOB PLANTIO DIRETO NO DISTRITO FEDERAL

\author{
Fernando M.Krahenbuhl' ${ }^{1}$, Luiz C. B. Nasser ${ }^{2}$, Roberto V. Santos ${ }^{3}$, D Macalady ${ }^{4}$.
}

${ }^{1}$ Geólogo. Instituto de Geociências, Universidade de. Brasília, Campus Darcy Ribeiro; Brasília, DF, Brasil. 70000-000. e-mail: fernandokrahenbuhl@ hotmail.com (Bolsista CNPQ)

${ }^{2}$ Agrônomo Embrapa Cerrados (CPAC), Rodovia BR 020 km 40, Planaltina, DF, Brasil. 73301-970.e-mail: nasser@cpac.embrapa.br

${ }^{3}$ Geólogo. Instituto de Geociências, Universidade de. Brasília, Campus Darcy Ribeiro; Brasília, DF, Brasil. 70000-000. 000 e-mail: rventura@unb.br

${ }^{4}$ Químico.Colorado School of Mines, Golden, CO, USA.

\section{RESUMO}

O destino de um agrotóxico no meio ambiente depende de vários fatores, entre estes as alguns atributos do solo como mineralogia, composição química e conteúdo de matéria orgânica. Este estudo teve como objetivos verificar de que forma a adaptação de algumas das características de um Latossolo Vermelho Escuro do cerrado ao uso continuado do plantio direto (PD) influencia a retenção da atrazina e dois de seus principiais metabólitos (desetilatrazina e hidroxiatrazina). Desta forma, além da caracterização do solo, desenvolveram-se estudos da interação do solo com a atrazina, tanto com solos utilizados para PD, quanto solos de mata nativa nunca usados na prática agrícola. A comparação entre ambos evidenciou que as mudanças ocasionadas pelo solo agrícola, embora pequenas, foram suficientes para causar ligeira modificação na afinidade deste pelos compostos estudados. Atrazina e desetilatrazina apresentaram maior afinidade com os horizontes mais ricos em matéria orgânica, enquanto que os horizontes mais profundos, mais pobres em matéria orgânica, a adsorção da atrazina foi desprazível, desetilatrazina esta presente, porém em quantidades pequenas.

Palavras chave: desetilatrazina, hidroxiatrazina, lixiviação, plantio direto.

\begin{abstract}
The environmental fate of a pesticide depends on many factors, among them the soil characteristics as mineralogy, soil chemistry and organic matter content. This study aims to verify how the adaptation of chemical and mineralogical properties of a dark red latosol from the Brazilian savanna under the continuous use of no till practice can affect its affinity to atrazine and two metabolites (deethylatrazine and hydroxyatrazine). Therefore, beyond the characterization of the cited parameters, batch studies were performed with both no till and native vegetation soils. The comparison between them showed that the changes in some soil properties due to agriculture use of it were enough to change significantly its affinity for the studied compounds. Atrazine and deethylatrazine showed significant affinity to the high organic matter content horizon, while deeper horizons with smaller amounts of organic matter atrazine sorption was neglectible, deethylatrazine was present, but in smaller amounts.
\end{abstract}

Key words: deethylatrazine, hydroxyatrazine, lixiviation, no till.

\section{INTRODUÇÃO}


A prática do plantio direto (PD), tem sido associada por alguns autores à redução da poluição ambiental por agrotóxicos, principalmente do lençol freático (Landers, 1994 e Saturnino \& Landers, 1997). O uso continuado desta prática acarreta diversas modificações nas propriedades físicas, químicas e biológicas do solo (Sadeghi \& Isensee, 1992; Uri et al. 1998 e McGarry et al., 2000). Entretanto ainda não está claro de que forma estas modificações causadas pelo uso do PD interferem no comportamento de certos compostos em ambientes naturais.

Os principais benefícios causados pelo PD ao solo são o acréscimo de matéria orgânica (MO) e suas consequiências, o aumento da porosidade e a especiação da microfauna, principalmente nas camadas superficiais (Blevins et al. 1983; Sadeghi \& Isensee, 1992 e Uri et al. 1998).

Enquanto alguns autores sugerem que o uso do PD possibilita a diminuição ou até mesmo a eliminação do uso de agrotóxicos (Almeida, 1988 e Fornarolli, 1999), freqüentemente o que ocorre é um uso maior de herbicidas que outras práticas agrícolas (Oliveira, 2001). Este fato associado ao não revolvimento e a conseqüente preservação de canais no solo, podem resultar no aumento do risco de lixiviação de agrotóxicos para horizontes mais profundos do solo (Ogden et al. 1999).

Foi objetivo deste trabalho verificar como a modificação de atributos químicos e mineralógicos de um Latossolo Vermelho Escuro usado em PD em uma área de cerrado afeta a interação de atrazina e seus metabólitos quando comparado com um solo sem uso agrícola.

\section{MATERIAIS E MÉTODOS}

As amostras de Latossolo Vermelho Escuro Distrófico foram colhidas em uma área na porção leste do Distrito Federal (Figura 1). A região apresenta intensa atividade agrícola, com predomínio de plantio direto, produzindo principalmente grãos (feijão, milho e soja), hortaliças, frutas e frango de corte (Dolabella, 1996). A área escolhida pertence a Cooperbrás, que mantém um rigoroso controle sobre os insumos aplicados.

Foram abertos quatro poços dois em área de PD e outros dois em área de cerrado, os quais tiveram profundidades em torno de 3 a 3,5 metros nos quais as amostras foram colhidas nas paredes laterais. O número de amostras gerado dependeu do objetivo da amostragem: o primeiro poço (PP) foi escavado em uma área de PD onde são cultivados em sistema de rotação de culturas feijão, milho e soja sem irrigação desde 1995, com histórico de uso de atrazina conforme especificação do fabricante. Na época da amostragem, a área estava sendo cultivada com milho. $\mathrm{O}$ segundo poço (PC) foi escavado em uma área adjacente com vegetação nativa de cerrado e sem histórico de uso agrícola.

Foram gerados dois grupos de amostras. O primeiro destinado a análises físicas, químicas e mineralógicas realizadas nos laboratórios de geoquímica da Universidade de Brasília (UnB) e de solos do Centro de Pesquisa Agropecuária dos Cerrados da Embrapa (CPAC) em Planaltina. O segundo grupo, coletado com base nos resultados destas análises, foi formado por amostras compostas, destinou-se aos estudos da interação do solo (adsorção) com a atrazina e seus metabólitos e suas análises foram realizadas em Golden, na Colorado Scholl of Mines (CSM) - Estados Unidos.

Após coletadas as amostras foram secas ao ar, destorroadas e peneiradas e obtida a fração com tamanho inferior a $2 \mathrm{~mm}$. No primeiro grupo de amostras foram analisados: 
pH em água e em $\mathrm{KCl}$, teores de $\mathrm{MO}, \mathrm{SiO}_{2}, \mathrm{TiO}_{2}, \mathrm{Al}_{2} \mathrm{O}_{3}, \mathrm{Fe}_{2} \mathrm{O}_{3}, \mathrm{MgO}$ e $\mathrm{CaO}$, além da mineralogia por difratometria de raios-X (DRX) e gravimetria. As análises dos elementos maiores $\left(\mathrm{SiO}_{2}, \mathrm{TiO}_{2}, \mathrm{Al}_{2} \mathrm{O}_{3}, \mathrm{Fe}_{2} \mathrm{O}_{3}, \mathrm{MgO}\right.$ e $\left.\mathrm{CaO}\right)$, foram realizadas com abertura total das amostras por fusão alcalina com $\mathrm{NaOH}$ em cadinho de níquel, seguida de leitura por espectroscopia de emissão com fonte de plasma (ICP-AES), segundo método descrito por Boaventura (1991).

As amostras destinadas ao estudo da interação compostos-solo foram coletadas, embaladas em sacos plásticos e acondicionadas em caixa de isopor. A temperatura interna foi mantida em torno de $0{ }^{\circ} \mathrm{C}$. A caixa com as amostras foi então transportada para os laboratórios da CSM, onde foram abertas e as amostras acondicionadas em refrigerador a 4 ${ }^{\circ} \mathrm{C}$ até o momento da análise. Todo o procedimento de amostragem e transporte durou 48 horas. Uma vez nos laboratórios uma porção da amostra foi separada, seca em estufa (50 ${ }^{\circ} \mathrm{C}$ ) por 24 horas, destorroada, quarteada e peneirada em peneira com malha de $2 \mathrm{~mm}$.

Para os estudos de batelada de 5 gramas de amostra tratada (sem MO) ou 10 gramas de solo íntegro, ambos em duplicata, as amostras foram pesados em tubos de ensaio de plástico de $50 \mathrm{ml}$. A este solo foram então adicionados $45 \mathrm{~mL}$ da solução com a mistura atrazina $(10 \mathrm{mg} / \mathrm{L})$, desetilatrazina $(10 \mathrm{mg} / \mathrm{L})$ e hidroxiatrazina $(5 \mathrm{mg} / \mathrm{L})$, previamente preparada em uma solução $0,01 \mathrm{~N}$ de $\mathrm{CaCl}_{2}$. Os tubos de ensaio permaneceram, então, em um agitador horizontal, por 72 horas. Ao final deste tempo, as amostras foram centrifugadas por 30 minutos a $3500 \mathrm{rpm}$. O sobrenadante, cuidadosamente recolhido com pipeta Pasteur, foi filtrado e transferido para frasco volumétrico $(50 \mathrm{ml})$ e analisado por cromatografia líquida de alta performance (high performance liquid chromatography, HPLC). Os resíduos remanescentes no solo foram extraídos em duas etapas: na primeira etapa utilizou se $30 \mathrm{~mL}$ de uma mistura (1:1volume:volume) de acetonitrila e água, que permaneceu em agitação por 4 horas. Depois da centrifugação nas mesmas condições acima descritas o sobrenadante foi recolhido com pipeta e transferido para balão volumétrico de $50 \mathrm{~mL}$. Na segunda etapa, $20 \mathrm{~mL}$ da mesma mistura (acetonitrila:água) foram usados, após nova agitação por 2 horas o procedimento de centrifugação foi repetido e o sobrenadante adicionado ao mesmo frasco do primeiro (extrato). Quando necessário, o volume de $50 \mathrm{~mL}$ foi completado com acetonitrila. Amostras em branco (sem solo) foram utilizadas para controle da adsorção pelas paredes dos frascos e submetidas ao mesmo procedimento das demais.

Para a identificação e quantificação dos compostos foi utilizada cromatografia líquida de alta performance (HPLC) em aparelho Hewlett Packard serie 1100, equipado com coluna eclipse XDB C18; 4,6x250 mm; 5 mícron a $35{ }^{\circ} \mathrm{C}$. Foram injetados $20 \mu \mathrm{L}$ de solução a um fluxo de $1 \mathrm{~mL} / \mathrm{min}$, utilizou se o sistema de auto-injeção com limpeza da agulha em acetonitrila após cada análise. O detector foi calibrado a $254 \mathrm{~nm}$ (uv) e o tempo total de bombeamento foi de 20 minutos. Foi utilizada ainda uma eluição em gradiente (Figura 2). Os parâmetros da análise foram extraídos conforme descrito por Sigma-Aldrich (1999), sendo modificados o volume injetado e o tamanho da coluna.

Os coeficientes de distribuição líquido/solo $(\mathrm{Kd})$ foram calculados através da fórmula: $\quad \mathrm{Kd}=\mathrm{Cs} / \mathrm{Cl}$, onde $\mathrm{Cs}$ é a concentração no solo e $\mathrm{Cl}$ a concentração no líquido, ambos ao final do experimento. 


\section{RESULTADOS E DISCUSSÃO}

No solo estudado a maioria dos horizontes apresentaram espessuras muito próximas em ambos os perfis, exceto o horizonte BW1 do perfil da plantação de milho, cuja espessura foi consideravelmente maior que no perfil do cerrado. Predominaram as colorações avermelhadas com matiz 2,5 YR ou mais escuras, indicativa de um ambiente oxidante, típico desta classe de solos. As características dos poços estão descritas na Tabela 1 .

\section{Análises químicas e mineralógicas}

Os resultados dos estudos de DRX mostraram grande semelhança entre os dois perfis. Os principais minerais foram: caulinita, gibbsita, quartzo, hematita, goethita e anatásio, mineralogia típica encontrada por outros autores em solos semelhantes do Distrito Federal (Reatto et al, 1999 e Vasconcelos 2000). Não houve variação qualitativa na mineralogia em função da profundidade.

A gibbsita se apresentou em maior quantidade na fração silte, diminuindo nas frações mais finas. Também o quartzo mostrou-se mais abundante nas frações mais grosseiras, sendo que este foi ainda mais cristalino nas amostras mais profundas, como no horizonte $\mathrm{C}$.

As amostras da fração argila submetidas a aquecimento não resultaram no desaparecimento do pico relativo a caulinita, enquanto os picos da goethita e da gibbsita desapareceram. Este fato indica maior cristalinidade da caulinita (Vasconcelos, 2000).

As análises termogravimétricas mostraram poucas diferenças no conteúdo de caulinita nos dois perfis estudados, este é o principal mineral presente tanto na área de PD quanto no cerrado. As maiores concentrações foram encontradas nos horizontes superiores, com ligeiro predomínio no solo do cerrado. Em profundidade houve uma diminuição de seu conteúdo em ambos os poços (Figura 3).

A quantidade de gibbsita nos dois poços foi aproximadamente a mesma, em torno de $18 \%$, com pequena variação com a profundidade. Somente no horizonte C a quantidade deste mineral foi muito menor que nos demais horizontes (Figura 3).

As análises químicas mostraram padrão condizente com um latossolo (Tabela 2). Considerando o horizonte $\mathrm{C}$ como aquele que tem a composição química mais próxima da rocha original, observa-se que os elementos mais móveis como $\mathrm{Si}, \mathrm{Mg}$ e Ca tiveram suas concentrações diminuídas nos horizontes superiores em relação a este, indicando que houve lixiviação nos solos do cerrado. Por outro lado, os elementos como Ti e Fe tem suas concentrações maiores nos horizontes A e B, o que pode ser explicado pela sua imobilidade em um processo de lateritização e conseqüente enriquecimento relativo. As principais diferenças entre os dois solos ocorreram nos horizontes superficiais, com o solo sob PD apresentando maior conteúdo de $\mathrm{MO}$ e pH menos ácido que o solo do cerrado. Estas diferenças provavelmente decorrem do uso de insumos para correção do solo agrícola.

\section{Ensaios de adsorção}

Os resultados obtidos nos ensaios de adsorção realizados com as três substâncias são apresentados na Figura 4 e os percentuais em cada meio físico ao final do experimento expressos na Tabela 3. As amostras de branco mostraram que não houve adsorção pelas paredes dos frascos. 
Observa-se que embora não hajam grandes variações nas quantidades adsorvidas nos dois tipos de solos, percentualmente as quantidades adsorvidas ao horizonte superficial do solo sob PD foram ligeiramente maiores (em torno de $5 \%$ ) que no solo sob cerrado para todos os compostos. Este horizonte é também o que apresenta a maior quantidade de MO, indicando que é com este componente do solo que se dá a maior interação.

Dentre os compostos estudados a atrazina foi o que apresentou a maior semelhança quanto ao comportamento nos diferentes horizontes dos dois tipos de solo. A concentração do horizonte A dos dois poços ficou em torno de $8 \mathrm{mg} / \mathrm{kg}$ e pouco foi encontrado associado aos horizontes mais profundos. Também foi o composto que apresentou a maior porcentagem adsorvida pelo solo $(31,5$ e $25,79 \%$ respectivamente no PD e no cerrado), superando até mesmo a hidroxiatrazina que teoricamente apresenta afinidade maior com a MO.

O percentual de desetilatrazina adsorvido aos solos do PD e do cerrado foi inferior ao da atrazina (25,94 e 20,99 \% respectivamente). Por apresentar propriedades físicoquímicas distintas como maior solubilidade em água e menor afinidade com a matéria orgânica, este fato já era esperado, porém, ainda assim, o solo do PD apresentou maior quantidade do composto adsorvido do que o do cerrado. Nos horizontes mais profundos e com menor teor de $\mathrm{MO}$, as quantidades adsorvidas, foram maiores do que as de atrazina em ambos os poços. Isto pode representar uma maior afinidade com a fração mineral do solo.

Também a hidroxiatrazina, no horizonte A em solo sob PD apresentou concentrações maiores do que sob cerrado. Este composto, por sua baixa solubilidade em água deveria apresentar maior afinidade com a fração orgânica do solo, pois as ligações envolvidas em geral são mais fortes. Nos horizontes mais profundos, sobretudo no horizonte $\mathrm{C}$, foi o composto que apresentou a maior retenção, mais uma vez sugerindo interação com a fração inorgânica do solo.

Os coeficientes de distribuição solo/líquidos (Kd) (Figura 5) apresentaram variações nos dois tipos de solo. Quanto maior o seu valor, maior será a afinidade do composto pelo solo e menor a possibilidade de lixiviação para o lençol freático.

Observa-se mais uma vez que os valores de $\mathrm{Kd}$ associados ao horizonte superficial, solo do PD, foram maiores do que os apresentados pelo horizonte equivalente no solo do cerrado. Em profundidade, esta diferença diminui. Na prática estes resultados significam que os compostos são menos móveis no horizonte superficial, com maior teor de MO em ambos os solos, e mais móveis nos horizontes mais profundos.

Os estudos químicos e mineralógicos em solos destinados ao PD e sem uso agrícola mostraram poucas diferenças entre si. As diferenças mais evidentes ocorreram no conteúdo de $\mathrm{MO}$ e no $\mathrm{pH}$ das camadas superficiais. Estas diferenças, porém, foram suficientes para modificar a afinidade deste solo para com os compostos estudados. De forma geral, o solo sob PD foi capaz de reter em média 5\% mais do que o solo sob cerrado.

Os valores de Kd encontrados indicam afinidade da atrazina com a MO dos solos, de modo que nos horizontes mais ricos há maior retenção dos compostos. Estes valores estão de acordo com os encontrados por outros autores em diferentes tipos de solos (Roy \& Krapac, 1994 e Moreau \& Mouvet, 1997).

A maior capacidade de reter os compostos associados ao solo do PD não significa que este solo não apresente perigo de contaminação do lençol freático, uma vez que esta adsorção está associada principalmente aos sítios da matéria orgânica podendo ser revertida. Não foram analisados nesta pesquisa os efeitos da estrutura do solo sob PD na lixiviação dos compostos.

\section{LITERATURA CITADA}


ALMEIDA, F. S. Alopatia e as plantas. Londrina: IAPAR. 1988. 60 p.

BLEVINS, R. L.; SMITH, M. S.; THOMAS, G. W. e FRYE, W. W., Influence of conservation tillage on soil properties. Journal of Soil and Water Conservation, v. 38, p.301-305. Mai-jun 1983.

BOAVENTURA, G. R., Performance do espectrômetro de emissão com plasma (ICP), Spectroflame FVMO3, para determinação de 20 elementos químicos nas amostras de referência geoquímica DNC-1, W-2, UNB-B1 e UNB-G1. In: CONGRESSO BRASILEIRO DE GEOQUÍMICA. 3, São Paulo, 1991. Anais. SBGq, 1991. v. 2, p.423426.

DOLABELLA, R. H. C., Aspectos ambientais e agronômicos da agricultura irrigada na bacia do rio Jardim, Distrito Federal. In: SIMPÓSIO SOBRE O CERRADO, 7, Brasília, 1996. Anais. 1996. p. 249-252.

FORNAROLLI, D. A., Influência da cobertura morta no comportamento do herbicida atrazine. In: CONGRESSO BRASILEIRO DE CIÊNCIA DO SOLO, 27, Brasília, 1999. Anais eletrônicos (CD ROM). 1999. SBCS.

LANDERS, J. N., Fascículo de experiências de PD no cerrado. Brasília: Associação de PD no Cerrado, 1994. 261 p.

McGARRY, D.; BRIDGE, B. J. e RADFORD, B. J. 2000. Contrasting soil physical properties after zero and traditional tillage of an alluvial soil in the semi-arid subtropics. Soil \& Tillage Research, 53: 105-115.

MOREAU, C. \& MOUVET, C., Sorption and desorption of atrazine, deethylatrazine, and hydroxyatrazine by soil and aquifer solids. Journal of Environmental Quality, v. 26, p.416-424. Mar-abr 1997.

OGDEN, C. B.; ES, H. M.; WAGENET, R. J. e STEENHUIS, T. S., Spatial - temporal variability of preferential flow in a clay soil under no-till and plow-till. Journal of Environmental Quality, v. 28, p.1264-1273. Jul-ago 1999.

OLIVEIRA, M. F.; ALVARENGA, R. C.; OLIVEIRA, A. C. e CRUZ J. C., Efeito da palha e da mistura atrazine e metolachlor no controle de plantas daninhas na cultura do milho, em sistema de plantio direto. Pesquisa Agropecuária Brasileira. V.36, n. 1, disponível na internet jan 2001.

REATTO, A.; MARTINS, E. S.; GUIMARÃES, E. M.; SPERA, S. T.; CORREIA, J. R. e SIMM, K. M. C. B., Variabilidade mineralógica de latossolos na bacia do rio Jardim, DF. Brasília: Emprapa, 1999. 24 p.

ROY, W. R. \& KRAPAC, I. G., Adsorption and desorption of atrazine and deethylatrazine by low organic carbon geologic materials. Journal of Environmental Quality, v. 23, p.549-556, mai-jun 1994. 
SADEGHI, A. M. \& ISENSEE, A. R. Effect of tillage systems and rainfall patters on atrazine distribution in soil. Journal of Environmental Quality, v. 21, p.464-469, jul-set 1992.

SATURNINO, H. M. \& LANDERS, J. N., O meio ambiente e o PD. Goiânia: Associação de PD no Cerrado, 1997. 116p.

SIGMA-ALDRICH.,Discovery agricultural applications book. Bellefonte (PA/EUA): Supelco. $1999.8 \mathrm{p}$.

URI, N. D.; ATWOOD, J. D. e SANABRIA, J., An evaluation of the environmental costs and benefits of conservation tillage. Environmental Impact Assessment Review, v.18, p.521-550. 1998.

VASCONCELOS, F. M., The role of natural organic matter (NOM) in the sorption of copper to Brazilian oxisols. Tese de doutorado. Departamento de química. Colorado School of Mines. Golden, CO, EUA. 2000. 225p. 
Tabela 1 - Descrição dos perfis dos poços do Cerrado (PC) e do Plantio Direto (PP).

\begin{tabular}{|c|c|c|c|}
\hline Horizonte & Amostra & Profundidade & Descrição \\
\hline \multicolumn{4}{|c|}{ POÇO DO CERRADO } \\
\hline A & PCA & 0 a $20 \mathrm{~cm}$ & $\begin{array}{l}\text { Vermelho escuro (2.5YR 3/4); argiloso (53\% de argila, } 27 \% \text { de } \\
\text { silte, } 18 \% \text { de areia fina e } 2 \% \text { de areia grossa); estrutura em blocos } \\
\text { subangulares pequenos, fracos a moderados que se desfaz em } \\
\text { granular muito pequena e forte; plástico, e pegajoso. }\end{array}$ \\
\hline $\mathrm{AB}$ & & $20 \mathrm{a} 40 \mathrm{~cm}$ & $\begin{array}{l}\text { Vermelho ( } 2.5 \text { YR } 4 / 6) \text {; argiloso; estrutura em blocos subangulares } \\
\text { médios e fracos; plástico, ligeiramente pegajosa. }\end{array}$ \\
\hline BA & & 40 a $76 \mathrm{~cm}$ & $\begin{array}{l}\text { Vermelho ( } 2.5 \mathrm{YR} 4 / 8) \text {, argiloso; estrutura em blocos angulares } \\
\text { médios e fracos; plástico, pouco pegajoso. }\end{array}$ \\
\hline BW1 & \multirow{5}{*}{ PCB } & 76 a $113 \mathrm{~cm}$ & $\begin{array}{l}\text { Vermelho (10R 4/8), argiloso (argila } 58 \% \text {, silte } 23 \% \text {, areia fina } \\
17 \% \text { e areia grossa } 2 \% \text {; estrutura em blocos grandes e fracos; }\end{array}$ \\
\hline & & & $\begin{array}{l}\text { plástico e pouco pegajoso; poucas concreções ferruginosas } \\
\text { pequenas e arredondadas. }\end{array}$ \\
\hline BW2 & & & Vermelho (10R 4/8); argiloso (argila 57\%, silte $21 \%$, areia fina20 \\
\hline \multirow[t]{2}{*}{ BW3 } & & 113 a $141 \mathrm{~cm}$ & $\begin{array}{l}\text { \% e areia grossa } 2 \% \text { ); estrutura granular muito pequena e fraca } \\
\text { com aspecto de maciça porosa pouco coerente; muito plástico; } \\
\text { com concreções ferruginosas com quartzo aprisionado (?); não } \\
\text { pegajoso. }\end{array}$ \\
\hline & & 141 a $190 \mathrm{~cm}$ & $\begin{array}{l}\text { Vermelho (10R } 4 / 8) \text {; argiloso (argila } 58 \% \text {, silte } 23 \% \text {, areia fina } \\
17 \% \text { e areia grossa } 2 \%) \text {; mosqueado; estrutura granular muito } \\
\text { pequena; muito plástico, não pegajoso, porém um pouco mais que } \\
\text { o anterior; mosqueamentos: bruno-acinzentado (10 YR } 6 / 2) \\
\text { bruno-amarelado claro (10 YR } 7 / 4) \text {; sistema radicular até } 1,9 \mathrm{~m} \text {. }\end{array}$ \\
\hline Concrecionário & & 190 a $230 \mathrm{~cm}$ & $\begin{array}{l}\text { Matriz argilosa plástica com concreções ferruginosas arredondadas } \\
\text { a subarredondadas com aproximadamente } 1,5 \mathrm{~cm} \text { em média. }\end{array}$ \\
\hline Quartzoso & & 230 a $254 \mathrm{~cm}$ & $\begin{array}{l}\text { Nível de quartzo branco, friável, com pequenos cristais } \\
\text { englobando material argiloso. }\end{array}$ \\
\hline $\mathrm{C}$ & PCC & 254 a $300 \mathrm{~cm}$ & $\begin{array}{l}\text { Vermelho (10 R 4/4); muito argiloso; sem estrutura; muitos } \\
\text { mosqueados; plástico. }\end{array}$ \\
\hline \multicolumn{4}{|c|}{ POÇO DO PLANTIO DIRETO } \\
\hline Ap & PPA & 0 a $16 \mathrm{~cm}$ & $\begin{array}{l}\text { Vermelho (2.5YR 3/8); argiloso; estrutura em grumos; duro, } \\
\text { plástico, não pegajoso; transição gradual; poucas raízes. }\end{array}$ \\
\hline $\mathrm{AB}$ & & 16 a $34 \mathrm{~cm}$ & $\begin{array}{l}\text { Vermelho (2.5YR 4/6); argiloso; maciço; muito duro, plástico, não } \\
\text { pegajoso; concreções ferruginosas alinhadas em torno de } 20 \mathrm{~cm} \\
\text { de profundidade. }\end{array}$ \\
\hline BA & & 34 a $90 \mathrm{~cm}$ & $\begin{array}{l}\text { Vermelho escuro ( } 2.5 \text { YR 3/6); argiloso; plástico, não pegajoso; } \\
\text { com concreções ferruginosas milimétricas e arredondadas. }\end{array}$ \\
\hline BW1 & \multirow{4}{*}{ PPB } & 90 a $200 \mathrm{~cm}$ & $\begin{array}{l}\text { Vermelho (10 R 4/8); argiloso; maciço; plástico, não pegajoso; } \\
\text { muitas concreções ferruginosas arredondadas, milimétricas a } \\
\text { centimétricas, às vezes em níveis }(116 \mathrm{~cm}) \text {; grãos de quartzo }\end{array}$ \\
\hline BW2 & & & arredondados (mm a cm); sistema radicular até $1,4 \mathrm{~m}$ \\
\hline \multirow{2}{*}{ BW3 } & & 200 a $230 \mathrm{~cm}$ & $\begin{array}{l}\text { Vermelho (10 R 4/8); argiloso; maciço; plástico, não pegajoso; } \\
\text { poucas concreções ferruginosas, milimétricas e arredondadas. }\end{array}$ \\
\hline & & 230 a $280 \mathrm{~cm}$ & 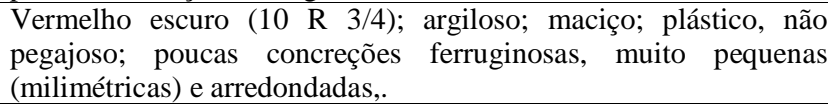 \\
\hline Concrecionário & & 280 a $300 \mathrm{~cm}$ & $\begin{array}{l}\text { Matriz argilosa plástica com concreções ferruginosas arredondadas } \\
\text { a subarredondadas com aproximadamente } 1,5 \mathrm{~cm} \text { em média. }\end{array}$ \\
\hline Quartzoso & & 300 a $330 \mathrm{~cm}$ & $\begin{array}{l}\text { Nível de quartzo branco, friável, com pequenos cristais } \\
\text { englobando material argiloso. }\end{array}$ \\
\hline $\mathrm{C}$ & PPC & 330 a $350 \mathrm{~cm}$ & $\begin{array}{l}\text { Vermelho escuro (10R 4/4); muito argiloso; sem estrutura; } \\
\text { plástico, com mosqueamento. }\end{array}$ \\
\hline
\end{tabular}


Tabela 2 - Composição química média (\%) por horizontes.

\begin{tabular}{c|cccccccccc}
\hline horizonte & $\mathrm{SiO}_{2}$ & $\mathrm{TiO}_{2}$ & $\mathrm{Al}_{2} \mathrm{O}_{3}$ & $\mathrm{Fe}_{2} \mathrm{O}_{3}$ & $\mathrm{MgO}$ & $\mathrm{CaO}$ & $\mathrm{PF}$ & $\mathrm{MO}$ & pH água & $\mathrm{pH} \mathrm{KCl}$ \\
\hline PCA & 39,10 & 1,59 & 27,22 & 14,07 & 0,80 & 0,32 & 16,13 & 2,14 & 5,03 & 4,00 \\
PCB & 41,00 & 1,74 & 27,48 & 13,33 & 1,03 & 0,31 & 14,94 & 0,51 & 5,31 & 5,39 \\
PCC & 52,08 & 1,44 & 25,24 & 10,03 & 1,24 & 0,37 & 8,93 & 0,14 & 5,45 & 4,10 \\
PPA & 39,43 & 1,51 & 26,33 & 12,17 & 0,53 & 0,36 & 18,20 & 2,71 & 5,90 & 5,07 \\
PPB & 36,79 & 1,33 & 24,96 & 18,48 & 0,67 & 0,30 & 15,56 & 0,71 & 5,22 & 5,19 \\
PPC & nd & nd & nd & nd & nd & nd & nd & 0,36 & nd & nd \\
\hline
\end{tabular}


Tabela 3. - Percentuais de atrazina, desetilatrazina e hidroxiatrazina nos horizontes A, B e $\mathrm{C}$ dos perfis de solos estudados sob cultivo em sistema de plantio direto e sob vegetação natural.

\begin{tabular}{|c|c|c|c|}
\hline & Líquido final (\%) & Solo (\%) & Total recuperado (\%) \\
\hline \multicolumn{4}{|c|}{ atrazina } \\
\hline PPA & 53,11 & 31,50 & 84,61 \\
\hline PPB & 90,97 & 0,25 & 91,22 \\
\hline PPC & 79,73 & 0,00 & 79,73 \\
\hline PCA & 67,33 & 25,79 & 93,12 \\
\hline PCB & 75,82 & 0,00 & 75,82 \\
\hline PCC & 79,51 & 0,00 & 79,51 \\
\hline \multicolumn{4}{|c|}{ desetilatrazina } \\
\hline PPA & 64,60 & 25,94 & 90,54 \\
\hline PPB & 92,47 & 8,06 & 100,53 \\
\hline PPC & 81,47 & 4,52 & 85,99 \\
\hline PCA & 80,73 & 20,99 & 101,72 \\
\hline PCB & 91,27 & 7,63 & 98,91 \\
\hline PCC & 95,40 & 5,60 & 100,99 \\
\hline \multicolumn{4}{|c|}{ hidroxiatrazina } \\
\hline PPA & 59,60 & 23,86 & 83,46 \\
\hline PPB & 88,95 & 7,98 & 96,93 \\
\hline PPC & 82,89 & 11,29 & 94,18 \\
\hline PCA & 67,69 & 18,22 & 85,91 \\
\hline PCB & 81,05 & 10,56 & 91,60 \\
\hline PCC & 80,89 & 11,10 & 91,99 \\
\hline
\end{tabular}




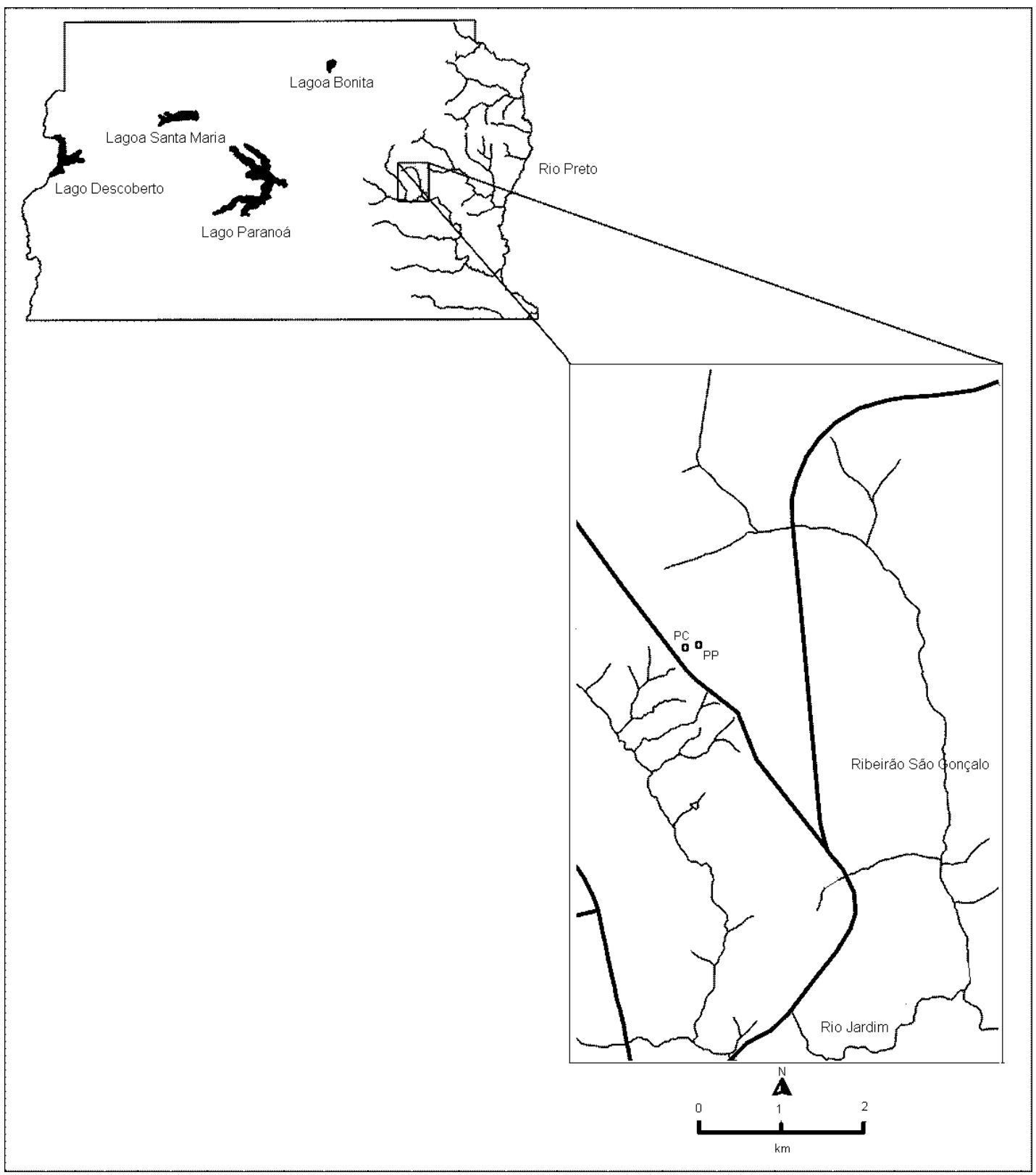

Figura 1 - Localização da área e pontos de amostragem. Modificado de IBGE (1984). 


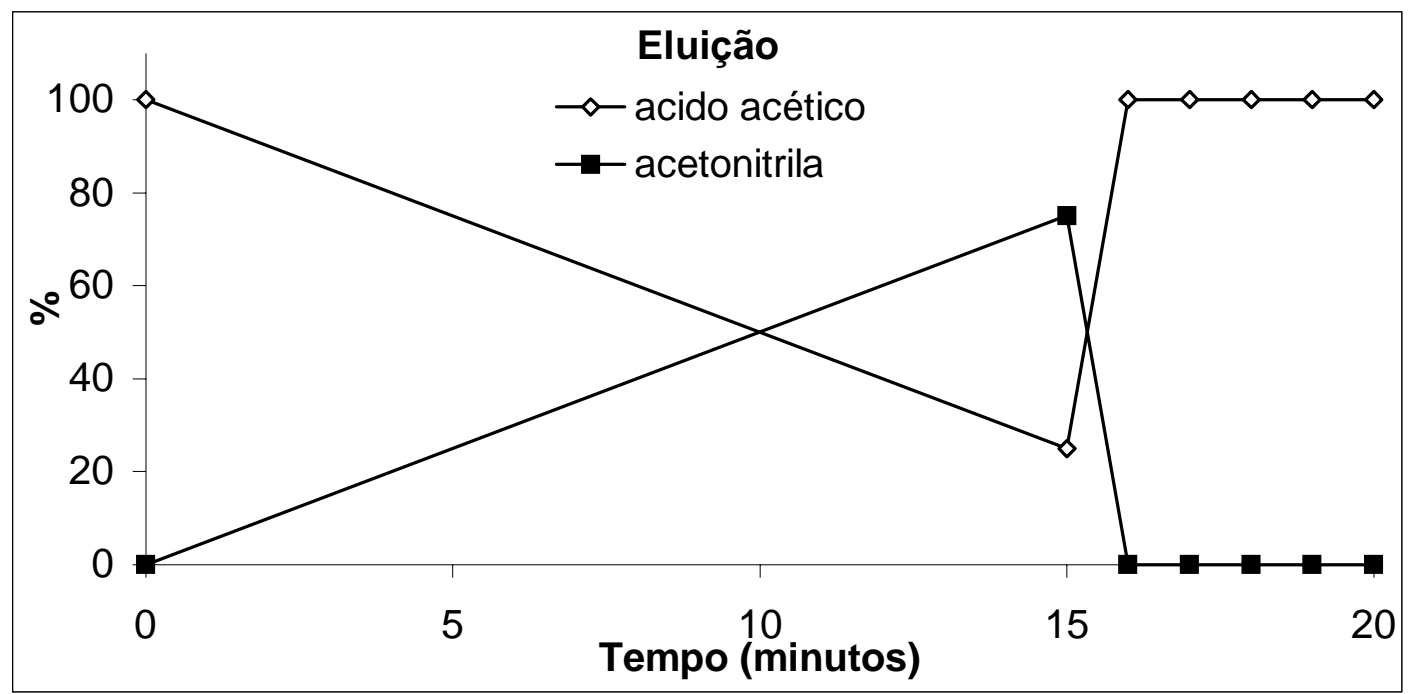

Figura 2 - Gráfico do gradiente da eluição. 
CAULTITA

GIBSTTA

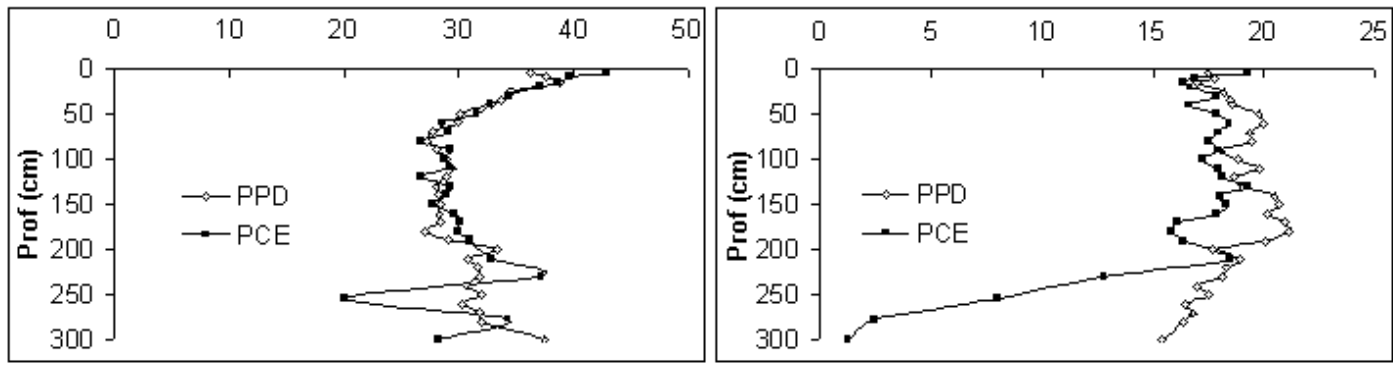

Figura 3 - Variação percentual de caulinita e gibbsita em função da profundidade. Obs.: $\mathrm{PPD}=$ poço do $\mathrm{PD}, \mathrm{PCE}=$ poço do cerrado. 

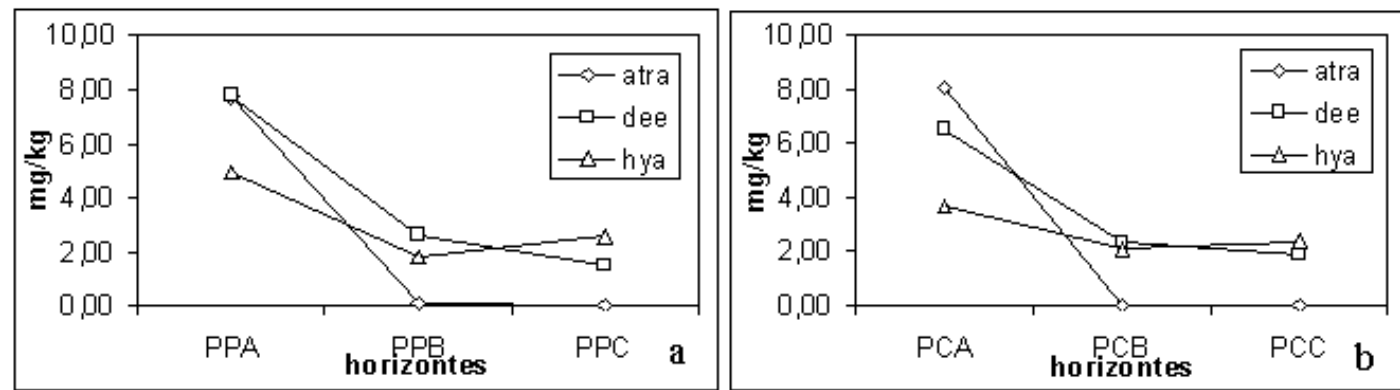

Figura 4 - Adsorção de atrazina (atra), desetilatrazina (dee) e hidroxiatrazina (hya) após 72 $\mathrm{h}$ de equilíbrio pelos horizontes do solo dos dois poços ( $\mathrm{mg}$ do composto/kg de solo): (a) PD e (b) cerrado. 


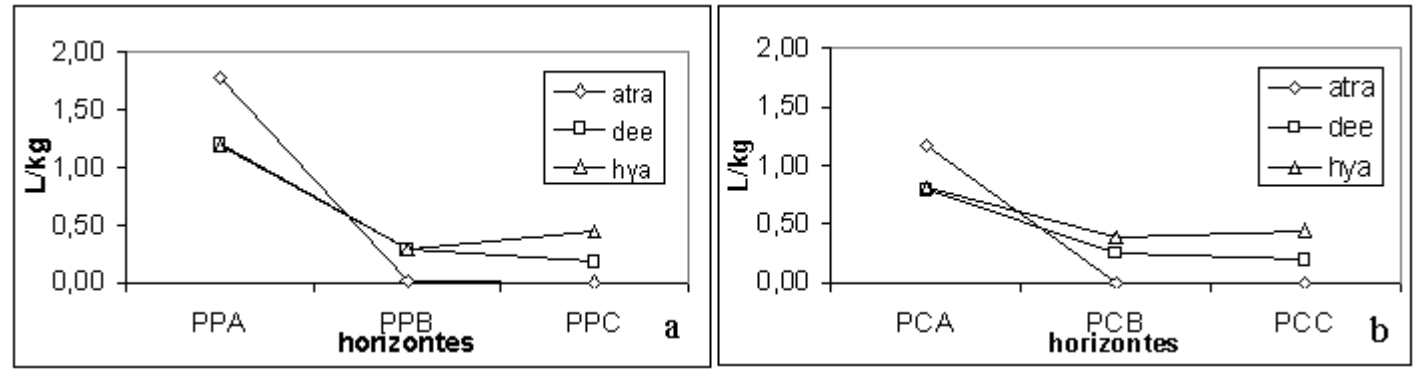

Figura 5 - Coeficiente de distribuição (Kd) (L/kg): (a) PD e (b) cerrado. 